\title{
NuRSES' KNOWLEDGE OF AND ATTITUDE TOWARDS EXERCiSE AS A TREATMENT METHOD FOR HYPERTENSIVE PATIENTS
}

\begin{abstract}
Aerobic exercise is used in treating hypertension. Even though physiotherapists are the first choice in presenting exercise treatment, few are available to do so in primary health clinics. Nurses are patients' first contact and may be able to fulfil this role. Nurses' knowledge and attitude towards exercise as a treatment method for hypertensive patients was determined. This descriptive study included all nurses (n=67) working in 23 Bloemfontein clinics. Forty-three nurses completed structured questionnaires that determined their knowledge of exercise as a treatment method. All nurses prescribed medication for

\section{Grobler L, M.HPE (UFS); Joubert G, BA, MSc ${ }^{3}$} Roets L, Ph.D'; Nel MM, Ph.D;

\author{
Departments of Physiotherapy and \\ 3 Biostatistics, \\ 1 School of Nursing, and \\ 2 Office of the Dean, Faculty of Health Sciences, \\ University of the Free State, Bloemfontein.
} hypertensive patients. Most nurses prescribed weight control (72.1\%), diet control (76.7\%), patient education (74.4\%), and life-style modification (72.1\%). Most (83.7\%) nurses were aware of exercise as a treatment method for hypertension. Only seven nurses, prescribing a brisk walk, recommended the correct type of exercise. The nurses' attitude towards exercise as a treatment method was determined using focus group interviews (n=16). Nurses reflected a positive attitude towards exercise with 198 positive responses. Nurses could express more than one opinion, all of which were recorded. Twenty responses reflected little or no knowledge, and four responses reflected an unsure/neutral attitude towards exercise. Ten responses reflected disinterest in prescribing exercise. Nurses do not have adequate knowledge to enable them to confidently prescribe exercise to patients. The need for more information was mentioned and some nurses were willing to present exercise classes. A training program, containing pertinent information, so that nurses can prescribe exercise for hypertension, needs to be developed.
\end{abstract}

\section{KEY WORDS: HYPERTENSION, EXERCISE, NURSES' KNOWLEDGE AND ATTITUDE.}

\section{INTRODUCTION}

Hypertension is a global disorder common to the white and black population (Milne 2001) and is a risk factor for cerebro-vascular accidents, congestive heart failure, chronic occlusive vascular disease and kidney failure. In the South African population aged 15 years and older, an estimated 3.3 million people suffer from hypertension with blood pressures $\geq 160 / 95 \mathrm{mmHg}$, and 6.1 million with blood pressures $\geq 140 / 90 \mathrm{mmHg}$ (Department of Health 1998). One million hypertensive patients receive treatment in Free State clinics per year. This represents 80000 visits per month (personal interview: Prof OM Bachmann, March 2002).

Hypertension is rated as one of the five most important diseases in the governmental restructuring and development programs (Primary Health Care 1996). Patients suffering from hypertension need lifelong therapy as it is a chronic illness (Milne 2001) and therapy should include a change to a healthier lifestyle. Aerobic exercise such as a brisk walk, running and cycling effectively increases a person's heart rate with a subsequent blood pressure decrease. Decreases of $-2.1 \mathrm{mmHg}$ for mean systolic blood pressure (Ebrahim \& Smith 1998) and as much as $-11 /-6 \mathrm{mmHg}$ (Arakawa 1996) have been recorded.

Regular exercise is one of the most cost-effective interventions in treating chronic illness (Fourie \& Steyn 1995). Goldstein determinded the effect of exercise on hypertension in a controlled study on men and women of different ages and with differing degrees of hypertension (Goldstein et al. 1988). A statistically significant reduction in average blood pressure was recorded for the participants of between -5.8 to $15.5 \mathrm{mmHg}$ systolic, and -5 to $-14 \mathrm{mmHg}$ diastolic. The aerobic exercises that were used included a brisk walk, running, cycling, swimming and callenetic exercise. The exercise sessions lasted 30-60 minutes and were performed 3-5 times per week.
Even though physiotherapists are the first choice when it comes to exercise treatment, few are available to do so in primary health care clinics. Nurses, however, have first contact with patients and contribute to their treatment and understanding of their condition. Hypertension patients' knowledge of their illness is often fragmented. Health care workers also deem that hypertension is not important enough to inform the patients that it should be controlled and that it is a chronic illness (Stewart et al. 1999). The nurses' knowledge of hypertension and the subsequent information

\section{CORRESPONDENCE TO:}

\section{Mrs L Grobler}

Department of Physiotherapy

University of the Free State

P.O. Box 339

Bloemfontein, 9300

Tel: (051) 401-3302

Fax: (051) 401-3304

Email: gnftlg@med.uovs.ac.za 
given to patients are also poor (Stewart et al 1999). Nurses have identified the need for additional training regarding the treatment of hypertensive patients (Tigar 1995).

The aim of this study was to determine the extent of nurses' knowledge at primary health-care clinic and their attitude towards exercise as a treatment method for patients with mild hypertension.

\section{METHODS}

This was a descriptive study. It includes all the nurses $(n=67)$ working in the 23 Bloemfontein primary health care clinics. The study was divided into two phases. The first phase determined nurses' knowledge of exercise as a treatment method for hypertensive patients by means of a structured questionnaire. The second phase determined nurses' attitude toward exercise as a treatment method of hypertensive patients by means of focus group interviews.

\section{Phase one}

A questionnaire was compiled after a literature search. It comprised the following:

- Demographics.

- Clinic section nurses were working in during time of study, plus percentage of hypertensive patients treated in that specific section.

- Knowledge of hypertension treatment and type of monitoring regarding treatment that was prescribed.

- Lifestyle changes and exercise in relation to hypertension treatment.

- Information given to hypertensive patients regarding exercise.

- Knowledge of exercise type and duration as well as precautions to be taken.

- Definition of hypertension per age group.

The questionnaire was completed during an in-house training session. To ensure the validity of the questionnaire, 3 domain experts (senior researchers in nursing and higher education) and a physiotherapy lecturer reviewed the questionnaire. Six nurses also took part in a pilot study, after which the questionnaire was amended accordingly. Nurses were given enough time to answer the questions and the researcher was available to answer any questions. To enhance the questionnaire's reliability it was developed according to the guidelines set up by Katzenellenbogen et al (1999).

\section{Phase two}

The focus group interviews took place as follows. The 23 clinics and nurses were randomly allocated into 3 groups. Thus, each group comprised of seven to eight nurses representing all the clinics in Bloemfontein. The number of focus groups depended on the point where saturation was reached (saturation was reached with the 3rd focus group: (De Vos 2002). A facilitator conducted the interviews in the presence of the researcher and each interview lasted a maximum of 90 minutes. The facilitator explained the purpose of the study and ensured confidentiality. The nurses had to discuss the following question: "What is your personal opinion and attitude concerning the value of exercise as a treatment method for hypertension patients?" The interviews were recorded on tape and fully transcribed later. Data were arranged in categories and themes and the following four categories emerged: positive attitude, lack of knowledge, unsure/neutral attitude and negative attitude.

Data from the questionnaires were analysed by the Department of Biostatistics of the University of the Free State and focus group interview data were analysed by the first author.

The Ethics Committee of the Faculty of Health Sciences, University of the Free State approved the study. For both phases all nurses gave written informed consent and participation was voluntary.

\section{RESULTS AND DISCUSSION}

Phase one - knowledge of exercise as a treatment method (questionnaire)

Forty-three $(64.2 \%)$ of the target population of 67 nurses completed the questionnaire. Of those who completed the questionnaire $(n=43), 40$ (93\%) were female and $3(7 \%)$ were male. Work experience $(83.7 \%)$ ranged from 3 to 29 years, with a median of 16 years. Twenty-four (66.7\%) nurses had a 4-year diploma, B.A Cur or B.Soc.Sc (Hon) degree, $3(8.3 \%)$ had grade 12 , and $9(25 \%)$ had grade 11 qualifications. All the nurses had treated hypertensive patients and $74 \%$ of the nurses worked in a hypertension clinic. Many had worked in poly-clinics $(65.2 \%)$ and geriatric clinics $(41.9 \%)$ where the treatment of hypertensive patients is possible as the prevalence of hypertension is high in the above 65-year age group (Weich el al. 1991). The nurses $(n=40)$; (three nurses did not answer this question) treated a median of 50 patients per week (range 2 - 1000 patients per week). It is, however, not possible to treat 1000 patients per week (as one nurse indicated) and this may not be a true reflection of the numbers of hypertensive patients this nurse treats.

All nurses indicated that they prescribed medication for hypertensive patients and stated that this was the preferred treatment method. Although medication plays an important role in the treatment of hypertension, it is not necessary in treating mild hypertension and a change in lifestyle can be used to lower patients' blood pressure (Joint National Committee 1997). Most nurses prescribed weight control $(72.1 \%)$ and also diet control $(76.7 \%)$ as treatment methods. The nurses prescribed patient education $(74.4 \%)$ and life-style modification $(72.1 \%)$ as treatment methods. Even though most nurses prescribed life-style modification as a treatment method, only $46.5 \%$ considered exercise as part of that modification. Nurses do not necessarily deem this aspect important, although it plays a significant role in lowering blood pressure (Papademetriou \& Kokinos 1996). Only $7 \%$ of the nurses prescribed stress management as a treatment method.

Most (69.8\%) nurses always, and 25.6\% often controlled the patients' prescribed treatment-regime. If exercise were part of the nurses' prescribed treatment, control thereof could lead to lowering patients' hypertension.

Most $(83.7 \%)$ nurses were aware of exercise as treatment method for hypertension. Out of this group, $86.1 \%$ noted that it was included in the nursing curriculum while the rest obtained the information from doctors (25\%), physiotherapists $(8.3 \%)$, other nurses $(5.6 \%)$, family $(2.8 \%)$ and the literature $(5.6 \%)$. 
The nurses were not precisely aware of what exercises to prescribe to patients. Only seven nurses, prescribing a brisk walk, recommended the correct type of exercise, while the other types of exercise would not lower patients' hypertension. Many nurses (41.9\%) recommended a slow walk as exercise. Exercise, effective in lowering hypertension includes brisk walks, cardiovascular (aerobic) exercise and cycling (Papademetriou \& Kokkinos 1996). Only $11.6 \%$ of the nurses had previously referred hypertensive patients to physiotherapists for exercise (physiotherapists are not, however, available at the nurses' clinics). The prescription of the wrong type of exercise might be the reason why some nurses doubt the effect of exercise as a treatment method for hypertensive patients.

All nurses except one indicated that hypertensive patients must exercise every day or at least three times a week. Both frequencies concur with the available literature (Gordon 1997). There was, however, little consensus between the nurses on the length of an exercise session and $42.8 \%$ nurses were not adequately informed to prescribe the correct duration of exercise, a situation that can negatively affect their patients. An exercise session needs to be at least 30 minutes in duration to be effective in significantly lowering hypertension (Goldstein et al. 1988).

The nurses were in general very unsure about precautions to be taken for hypertensive patients during exercise. Between $69.7 \%$ and $83.7 \%$ nurses did not indicate the correct precautions to be taken during an exercise session. Responses to precautions to be taken during exercise are given in Table 1. Between $69.8 \%$ and $83.8 \%$ of the nurses did not choose a specific precaution, which could be interpreted as a lack of knowledge. Ignorance about the precautions to be taken when patients experience negative reactions could be dangerous or fatal for patients if exercise sessions are not properly monitored (Durstine et al 1993).

The nurses' $(n=43)$ knowledge of the correct classification for hypertension was tested. Hypertension is given in the literature as $140 / 90 \mathrm{mmHg}$ for people older than 18 years who are not taking anti-hypertensive medication and are not acutely ill (Joint National Committee 1997). Even though hypertension for all age groups is measured according to the same criteria, different age groups were included in the questionnaire. Only $20.9 \%$ of the nurses knew the hypertension classification for the age group older than 30 years, $44.2 \%$ knew the correct classification for the 30 to 50 year age group, and $37.2 \%$ knew the correct classification for the over 50 year age group. There does not seem to be any uniformity in nurses' training with regard to the classification of hypertension with pregraduate, postgraduate, and continuing professional development offering differing classifications (Personal interview: M. Reid

Table 1: Responses to precautions taken during exercise.

\begin{tabular}{|l|l|l|l|l|}
\hline \multicolumn{1}{|c|}{ Precaution } & Correct & Incorrect & Unsure & $\begin{array}{c}\text { Not chosen } \\
\text { a precaution } \\
\mathrm{n}(\%)\end{array}$ \\
\hline Resting pulse & $6(13.9)$ & $0(0)$ & $5(11.6)$ & $32(74.5)$ \\
\hline Increase in pulse & $4(9.3)$ & $6(13.9)$ & $3(7.0)$ & $30(69.8)$ \\
\hline $\begin{array}{l}\text { Increase in } \\
\text { respiratory tempo }\end{array}$ & $2(4.6)$ & $5(11.6)$ & $4(9.3)$ & $32(74.5)$ \\
\hline $\begin{array}{l}\text { Perspiration } \\
\text { in face }\end{array}$ & $1(2.3)$ & $2(4.6)$ & $4(9.3)$ & $36(83.8)$ \\
\hline Nausea & $5(11.6)$ & $1(2.3)$ & $4(9.3)$ & $33(76.8)$ \\
\hline $\begin{array}{l}\text { A bnormal } \\
\text { tiredness }\end{array}$ & $4(9.3)$ & $3(7.0)$ & $4(9.3)$ & $32(74.4)$ \\
\hline Dizziness & $7(16.3)$ & $2(4.6)$ & $4(9.3)$ & $30(69.8)$ \\
\hline
\end{tabular}

Table 2: Themes identified in the positive attitude category towards exercise as a treatment method for hypertensive patients.

\begin{tabular}{|l|l|}
\hline Category & Theme \\
\hline Positive attitude & $\begin{array}{l}\text { Convinced of the advantages of exercise } \\
\text { Convinced of the effectiveness of exercise } \\
\text { Medication could be decreased or avoided } \\
\text { Hypertension is treatable } \\
\text { Some exercise may cause complications } \\
\text { Exercise must be managed effectively } \\
\text { The age groups in which hypertension is apparent } \\
\text { Profile of a hypertensive patient } \\
\text { Causes of hypertension } \\
\text { Correct type and frequency of exercise } \\
\text { Identified ineffective type of exercise } \\
\text { Factors to be taken into account when prescribing exercise } \\
\text { Advantages and control of exercise sessions } \\
\text { Hypertension prevention } \\
\text { Concomitant preventative measures } \\
\text { Patients must stay active } \\
\text { General comments }\end{array}$ \\
\hline
\end{tabular}


2002). For instance, professional nurses at the health care clinics in the Free State use the EDL (Standard Treatment Guidelines and Essential Drugs List for South Africa) for hypertension treatment guidelines. The ideal blood pressure is classified as between 140/90 $\mathrm{mmHg}$ and 160/95 mmHg (Primary Health Care 1996). Patients with mild hypertension are clinically valued as normal and left untreated.

Phase two - attitude tow ards exercise as a treatment method (focus group interviews)

The three focus group interviews were conducted with 16 nurses. Saturation was reached after the third interview. The responses were classified in the following four categories: positive attitude, lack of knowledge, unsure/neutral attitude and negative attitude.

\section{Positive attitude}

As expected, most nurses had a positive attitude towards exercise as a treatment method for hypertensive patients, giving 198 positive responses. Nurses could express more than one opinion, all of which were recorded. Seventeen themes could be identified from the positive responses (Table 2). Nurses indicated that exercise was advantageous, were convinced of its effectiveness and that medication could be decreased or avoided. Nurses were knowledgeable about the causes of hypertension, in which age groups hypertension is apparent and also the profile of a hypertensive patient. Anxiety was expressed about conditions, which might cause complications during exercise.

\section{Lack of knowledge}

Surprisingly some nurses had little or no knowledge of the advantages of exercise, with 20 responses reflecting complete lack of knowledge. The following two groups were identified: The one group mentioned that they were not aware that exercise was part of hypertension treatment and that nobody had ever mentioned it to them. The second group were scared to prescribe exercise because they were not trained to do so.

\section{Unsure/neutral attitude}

Four responses reflected an unsure/ neutral attitude towards exercise. Nurses mentioned that exercise is not the solu- tion to everything, for example, stress during joblessness. They were not sure that exercise would help in the treatment of hypertension, as most patients switch between clinics and nurses would not be able to exercise effective control.

\section{Negative attitude}

Ten responses reflected disinterest in prescribing exercise for hypertensive patients. Even though some nurses had the appropriate knowledge of exercises they chose not to implement it. They gave health care talks and advice, but concentrated on diet, salt intake, smoking, alcohol, stress and pain.

\section{CONCLUSIONS AND RECOMMENDATIONS}

The nurses' attitude towards exercise as a treatment method for hypertensive patients was positive even though they do not have adequate knowledge to prescribe exercise to patients with confidence. The need for more information was mentioned during focus group interviews. Some nurses were willing to conduct the exercise classes.

In Bloemfontein the nurses receive contradictory information with regards to the classification of hypertension. Many hypertensive patients are subsequently classified incorrectly and may not receive the appropriate treatment.

As nurses are the first contact hypertensive patients have with health care, a training program containing information on exercise for hypertension, need to be developed. The program could take the form of a video and brochure to address nurses' lack of knowledge in the areas considered in this study.

Attempts should be made to positively improve nurses' attitudes towards exercise as a treatment method for hypertensive patients. More knowledge of chronic diseases such as hypertension will surely help and nurses should gain the required knowledge.

\section{REFERENCES}

Arakawa K 1996 Effect of exercise on hypertension and associated complications. Hypertension Research 19(Suppl 1):S87-S91

Department of Health 1998 Hypertension, chronic obstructive pulmonary disease and asthma in adults. In: South Africa Demographic and Health survey - 1998
De Vos AS, Strydom H, Fouché CB, Delport CLS 2002 Research at grass roots. For the social sciences and human service professions Van Schaik, Pretoria

Durstine Larry J, King Abby C, Painter 1, Roitman Geffrey L, Zurin Linda D. 1993 ACSM's resource manual for guidelines for exercise testing and prescription (2nd ed). Lea \& Febiger, Philladelphia

Ebrahim S, Smith GD 1998 Lowering blood pressure: a systematic review of sustained effects of non-pharmacological interventions. Journal of Public Health Medicine 20:441-448

Fourie J, Steyn K (eds) 1995 Chronic diseases of lifestyle in South Africa: Review of research and identification of essential health research priorities. MRC Technical Report, Cape Town

Goldstein AP, Krasner L, Garfield SL, Blanchard EB, Martin JE, Dubbert PM 1988 Non-drug treatments for essential hypertension: psychology practitioner guidebook. Pergamon Press, New York

Gordon NF 1997 Hypertension. In: Durstine JL, Bloomquist LE, Figoni SF (eds) ACSM's exercise management for persons with chronic disease and disabilities. Human Kinetics, Champaign, IL

Joint National Committee 1997 The sixth report of the Joint National Committee on prevention, detection, evaluation, and treatment of high blood pressure. Archives of Internal Medicine 157:2413-2446

Katzenellenbogen JM, Joubert G, Abdool Karim SS 1999 Epidemiology. A manual for South Africa. Oxford University Press, Southern Africa

Milne FJ 2001 Hypertension clinical guideline. South African Medical Journal 91:161-172

Papademitriou V, Kokkinos PF 1996 The role of exercise in the control of hypertension and cardiovascular risk. Current Opinion in Nephrology \& Hypertension 5:459-462

Primary Health Care 1996 Standard treatment guidelines and essential drugs list for South Africa. CTP Book Printers, Cape Town

Stewart AV, Eales CJ, Shepard K 1999 The health behaviour of black hypertensive patients at a chronic diseases clinic in a depressed socio-economic area of Johannesburg, South Africa. South African Journal of Physiotherapy 55:11-17

Tigar F 1995 Patients prefer to discuss anti-hypertensive care with practice nurses. Professional Nurse 10:413

Weich DJV, Nienkemper MJ, Bester FCJ 1991 Hipertensie by die bejaarde. South African Journal of Continuing Medical Education 9:60-69 